\title{
Current spiritual practices in India and their impact on anxiety
}

\author{
Rachna Awatramani \\ Founder-Director Insight Counseling Services LLP. \\ E-mail - rachna.awatramani@gmail.com
}

\begin{abstract}
Background: Yoga and ancient Indian spiritual practices have been used since ancient times in the management of anxiety disorders. The following study was conducted to determine the effects of a spiritual care program on the anxiety of the participants.

Methods: The study included 67 adult participants and they participated in Siddha Samadhi Yoga as a part of a seven day residential programme. The study examined the anxiety levels before and after a spiritual practice called Siddha Samadhi Yoga also known as Science of Silence Yoga (SSY). Adults were tested on both state and trait anxiety pre and post of SSY during their seven day residential camp. The State Trait Anxiety Inventory was used in the assessment and the data was statistically analyzed.

Results: It was predicted that there would be a significant difference in both state and trait anxiety post SSY. The study found a significant difference in both state and trait anxiety pre and post the yoga programme $(\mathrm{p}<0.05)$.

Conclusions: Yoga may be a useful adjuvant to routine anxiety treatments and must be explored in the management of anxiety disorders. In this study an attempt has been made to understand how spiritual practices help in reducing anxiety in people and how spiritual practices in India can be supportive to psychology professionals.
\end{abstract}

Key words: anxiety, state anxiety, trait anxiety, state-trait anxiety inventory, Siddha Samadhi yoga, yoga.

(Paper received $-10^{\text {th }}$ May 2016, Peer review completed $-26^{\text {th }}$ May 2016, Accepted $-6^{\text {th }}$ June 2016)

\section{INTRODUCTION}

Spirituality guides to evolve oneself and gives meaning to one's life. It includes expressions like prayer, meditation, interactions with others or nature, and relationship with self, higher self and god. Religion is also one of the expressions of spirituality [1]. A person experiences a sense of peace, purpose, connection to others, beliefs about the meaning of life and contact with the true self and divine.

Psychology is the study of human behaviour and mind. The discipline combines all aspects of the human experience covering all age groups. In every possible setting and services, "the understanding of behavior" is the enterprise of psychologists. Anxiety is an emotion characterized by feelings of tension, worried thoughts and physical changes like increased blood pressure. People with anxiety disorders usually have recurring intrusive thoughts or concerns. They may avoid certain situations out of worry [2].

Sarason [3] defines anxiety as diffusion, vague, very unpleasant feeling of fear or apprehension. Numerical research in India on mental health issues like anxiety is largely inadequate.

There has always been a debate between spirituality and psychology and sometimes a clear split has been seen. On one end there is mainstream and established psychology that does not concern itself with issues of consciousness and spirit and rejects what is not scientifically quantifiable or significant and on the other end there is spirituality with a traditional view that the psyche as an unreal construct and believe that psychological work is an indulgent reinforcement of the story of the false self. Therefore, many psychotherapists and their clients who fail to access benefits of spirituality, and many teachers and 
participants of spirituality make mistake by rejecting the psychological knowledge, and they do not develop skills and practices to work with it adequately [4].

But between these poles there are different approaches that take into consideration both the individual and the impersonal perspective of experiences, validating and justifying that some aspects of human experience can be analytically confirmed, while others remain mystical but real.

Sudhir Kakar has clearly explained in his book the ancient healing traditions of India represented in the rituals of shamans, the teachings of gurus, and the precepts of the school of medicine known as Ayurveda. He has drawn from both Eastern and Western knowledge to show how traditional healers are different from Western psychiatrist [5].

The underlying relationship between spirituality and psychology is that both fields focus on the well being of the humans. Both guide an individual to identify its highest potentials. It also concentrates on the true self and its patterns of growth, malformation, integration, and its relationship to the blessed or the divine [6]. As part of this study, the researcher interviewed Mr. Chandrahas Umrania, (spiritual teacher, since 1994) about his perception on spirituality and anxiety, he stated "what I do in my class is all about human behavior and psychology along with spirituality, they both work together it cannot be any one". I asked him about his experience being a (guru) spiritual teacher, he very politely answered with a smile "Its my learning. Compassion, love, gratitude all is what a guru teaches and learns in the process of teaching. Guru wants a person to surrender his ego and not material things and once the ego is surrendered one will be able to reach to his or her highest potentials"

A research on traditional community resources for mental health with a report of temple healing from India, had studied the effects of temple stay with people having psychotic illness, they concluded that there was improvement in the symptoms of people with psychotic illnesses and they received no psychopharmacological or other somatic interventions during their stay in the temple. The temple served as an alternative to clinical psychiatric treatment for these people with psychotic illness, as there is limited availability of health services in India. The family caregivers of these patients also thought that most of the subjects had improved during their stay at the temple [7].

Another research on counseling psychology in India which studied the confluence of two traditions considered the Western and the traditional Indian approaches showed that both the approaches together could inform the development of a psychology of counseling that is empirically sound and culturally relevant to the Indian context [8].

There was also a research on effect of a spiritual care program on levels of anxiety with leukemia spirituality has a significant role in adapting to leukemia and coping with its consequent mental disorders such as anxiety. This study was hence performed to determine the effects of a spiritual care program on anxiety of patients with leukemia [9].

There is hardly any light on the current practices and the process of spirituality. The clear understanding of the effects of spiritual practice on a student and a spiritual teacher is somehow less, whereas in India, the (guru) teacher is given the highest respect and position. India is known for spiritual Gurus, and many spiritual gurus have gathered exceptional followers in India as well as globally. Spirituality has always drawn people from all over the world to India.

There are many Spiritual centres in India like Bhramakumaris, Isha Foundation, Art of Living, Rishi Vana Tust ect. The researcher approached Rishi vana trust for studying their program called SSY Founded by Guruji Rishi Prabhakar in 1974. SSY is the rediscovery of the ancient Vedic science of effortless and joyful living. SSY is their basic program of seven days which is conducted in their ashrams all over India and abroad.

The SSY program is based on "Pancha Kosha" (Five layers of our body) [10]

\section{Annamaya Kosha}

Annamaya Kosha is the physical body which needs nourishment to survive. The human being is a part of the food chain as any other creature (i.e. the mammals). In SSY more focus is on the raw food and also on the food that provides energy. 


\section{Pranamaya Kosha}

Pranamaya Kosha exists in the physical body, interactive and dependent. It is the vital shell that is full of life. The pranic flows are in the blood, lymphatic and nervous circulation. Breath is a life-principle and is a controllable expression. Through the regulation of the breath (Pranayama) other bodies can be positively influenced. SSY teaches pranayama and yoga mudras.

\section{Manomaya Kosha}

Manomaya Kosha, the inner organ is also interactive and dependent of the former two. It governs the faculties of perception and instinctual consciousness. It is the mind which can construct and destroy. They believe it is our sub consciousness that is formed by negative and positive experiences and where our Self has developed with its behaviour.). To activate this deep relaxation and meditation is taught.

\section{Vijnanamaya Kosha}

Vijnanamaya Kosha, the conscious body lies deeper than the previously described ones and is also interactive and dependent. Many group discussion and sharing takes place in the period of seven days.

\section{Anandamaya Kosha}

Anandamaya Kosha is the most subtle body and without its existence life is impossible. It interacts with the others like the sun affecting our planet. This blissful body beyond words is perceived in flashes only in short moments. Daily meditation is required to experience this state

These principles are taken into account when undergoing the seven-day residential camp.

\section{METHODOLOGY}

\section{Participants}

Participant included 67 adults, both male and females. They participated in the SSY Siddha Samadhi Yoga also known as Science of Silence Yoga, as part of their seven day residential program. The age group of the participants was from 18 years to 70 years

\section{Measures used}

The State-Trait Anxiety Inventory (STAI) (Spielberger, 1994) was used pre and post SSY program to measure the state and trait anxiety. The State-Trait Anxiety Inventory (STAI) is an introspective psychological inventory consisting of 40 self-report items pertaining to anxiety affect [11].

State anxiety (A-State) can be defined as fear, nervousness, discomfort, and the arousal of the autonomic nervous system induced temporarily by situations perceived as dangerous (i.e., how a person is feeling at the time of a perceived threat)

Trait anxiety (A-Trait) can be defined as a relatively enduring disposition to feel stress, worry, and discomfort

The participants were administered the STAI when they enrolled for SSY. During the camp, the participants have to maintain silence. They are also asked to surrender their cell phone for the entire period to prevent external distractions. The following activities were practiced for 7 days at the SSY camp:

1. Yoga

2. Pranayama (Breathing technique)

3. Mudra Pranayama

4. Meditation

5. The participants were provided with natural/organic food for 7 days, and there were regular sharing and discussion sessions in the evening on the topics like self-management, time management, balancing work and personal life, social responsibility and happiness.

6. Participants were also provided time for reflection, where they had to spend some time with themselves and write down their thoughts.

At the end of the seven days, the STAI was administered once again. 


\section{STATISTICAL ANALYSIS}

The statistical analysis was done by using SPSS 17 version. The paired sample $t$ test was used to calculate the significance in the mean difference between pre and post state and trait anxiety scores.

\section{RESULTS}

Table 1: Indicating t-value and significance before and after SSY

\begin{tabular}{|l|cc|l|}
\hline \multicolumn{1}{|c|}{ Anxiety } & Before & After & \\
\hline & $53.43 \pm 7.93$ & $36.93 \pm 6.77$ & $10.44\left(<0.001^{*}\right)$ \\
\hline State Anxiety & $54.16 \pm 8.32$ & $45.3 \pm 6.33$ & $7.93\left(<0.001^{*}\right)$ \\
\hline Trait Anxiety & \multicolumn{4}{|c|}{${ }^{*}$ Significant at 0.001 ( $\mathrm{t}$ test used in the assessment) }
\end{tabular}

The table above represents the scores of the 67 participants on state and trait anxiety inventory. A paired $t$ test for pair 1 (state anxiety scores before and after) and pair 2 (trait anxiety scores before and after) was computed. The $t$ value for pair 1 was 10.44. The $t$ value for pair 2 was 7.93 . Both values were found to be statistically significant at 0.01 level. It is clear from the mean scores that the anxiety level of the participants reduced after the SSY seven day residential camp. It is also observed that the scores of state anxiety along with trait anxiety had reduced which means that the spiritual practices like SSY not only helped in reducing the immediate anxiety like fear, nervousness, discomfort, but it also helped in reducing the trait anxiety levels which means it had an impact on the anxiety that was harbored for a long time in the participants and which had become a part of their personality.

\section{DISCUSSION}

The above results prove without doubt that subjects have benefited following the SSY program. There was a significant reduction in their anxiety scores both at the state and at the trait level. Implications of the study are tremendous as the program affects not just anxiety related to situations (state) but also anxiety related to long-term personal characteristics. A number of confounding factors were not considered in the assessment and personality of the individuals in the study was not assessed as well.

The size of the sample can be considered a limitation as a larger more homogenized sample would enable generalization of the results to a bigger group. Due to the lack of a control group, this cannot be considered a true experiment. Internal and external validity hence are weak.

\section{REFERENCES}

1. Burkhardt MA. Spirituality: An analysis of the concept. Holist Nurs Pract 1989;3(3):69-77.

2. Endler NS, Parker JD. Stress and anxiety: Conceptual and assessment issues. Stress Med 1990;6(3):243-8.

3. Cology L, Sarason BR. Study Guide to Abnormal Psychology: The Problem of Maladaptive Behavior. Prentice Hall; 1989.

4. Holt CL, Wang MQ, Caplan L, Schulz E, Blake V, Southward VL. Role of religious involvement and spirituality in functioning among African Americans with cancer: Testing a mediational model. J Behav Med 2011;34(6):437-48.

5. Kakar S. Shamans, mystics and doctors: A psychological inquiry into India and its healing traditions. University of Chicago Press; 1982.

6. Ruffing JK. Christian Spirituality: The Classics. Edited by Arthur Holder. New York: Routledge, 2009.

7. Raguram R, Venkateswaran A Ramakrishna J, Weiss M. Traditional community resources for mental health: a report of temple healing from India. BMJ 2002;325(7354):38-40. 
8. Arulmani G. Counselling Psychology in India: At the Confluence of Two Traditions. Appl Psychol 2007;56(1):69-82.

9. Thygeson MV, Hooke MC, Clapsaddle J, Robbins A, Moquist K. Peaceful play yoga: serenity and balance for children with cancer and their parents. J Pediatr Oncol Nurs 2010;27(5):276-84.

10. Prabhakar R. What is SSY, RSVK Trust. Retrieved January 12, 2016, from http://www.ssy.org

11. Spielberger CD. State-Trait anxiety inventory. John Wiley \& Sons, Inc.; 2010.

Acknowledgements - Nil

Source of Funding - Nil

Conflict of Interest - Nil 